8 - ORIGINAL ARTICLE ISCHEMIA-REPERFUSION

\title{
Sevoflurane preconditioning during myocardial ischemia-reperfusion reduces infarct size and preserves autonomic control of circulation in rats ${ }^{1}$
}

\author{
Rubens Campana Pasqualin', Cristiano Teixeira Mostarda ${ }^{\mathrm{II}}$, Leandro Ezequiel de Souza ${ }^{\mathrm{III}}$, Matheus Fachini Vane ${ }^{\mathrm{IV}}$, Raquel \\ Sirventev, Denise Aya Otsuki $^{\mathrm{VI}}$, Marcelo Luís Abramides Torres ${ }^{\mathrm{VII}}$, Maria Cláudia Costa Irigoyen ${ }^{\mathrm{VII}}$, José Otávio Costa Auler \\ $\mathbf{J r}^{\mathrm{IX}}$
}

DOI: http://dx.doi.org/10.1590/S0102-865020160050000008

${ }^{I} \mathrm{PhD}$, Faculdade de Medicina, Universidade de São Paulo (USP), Brazil. Conception and design of the study, analysis of data, manuscript writing. "PhD, Hypertension Unit, Experimental Division, Instituto do Coração (InCor), Hospital das Clínicas, Faculdade de Medicina, USP, Sao Paulo-SP, Brazil. Conception of the study, analysis of data, manuscript writing.

IIIGraduate student, Hypertension Unit, Experimental Division, Instituto do Coração (InCor), Hospital das Clínicas, Faculdade de Medicina, USP, Sao Paulo-SP, Brazil. Helped conduct the study, analysis of data.

${ }^{\text {IV }}$ Postgraduate student in Anesthesiology, Laboratory of Anesthesiology (LIM-08), Faculdade de Medicina, USP, Sao Paulo-SP, Brazil. Helped conduct the study, analysis of data, manuscript writing.

${ }^{v} \mathrm{PhD}$, Hypertension Unit, Experimental Division, Instituto do Coração (InCor), Hospital das Clínicas, Faculdade de Medicina, USP, Sao Paulo-SP, Brazil. Helped conduct the study, analysis of data.

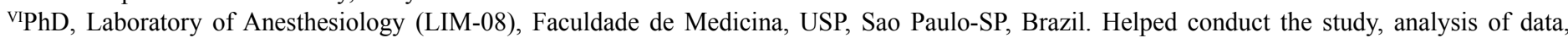
manuscript writing.

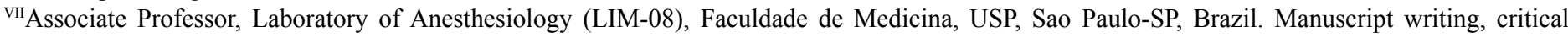
revision.

VIIIAssociate Professor, Hypertension Unit, Experimental Division, Instituto do Coração (InCor), Hospital das Clínicas, USP, Sao Paulo-SP, Brazil. Analysis of data, manuscript writing, critical revision.

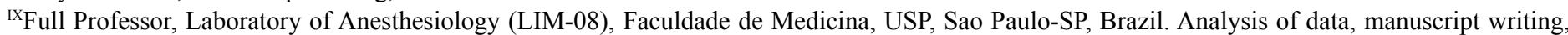
critical revision.

\section{ABSTRACT}

PURPOSE: To investigate the myocardial ischemia-reperfusion with sevoflurane anesthetic preconditioning (APC) would present beneficial effects on autonomic and cardiac function indexes after the acute phase of a myocardial ischemia-reperfusion.

METHODS: Twenty Wistar rats were allocated in three groups: control (CON, $n=10)$, myocardial infarction with sevoflurane (SEV, $\mathrm{n}=5$ ) and infarcted without sevoflurane (INF, $\mathrm{n}=5$ ). Myocardial ischemia (60 min) and reperfusion were performed by temporary coronary occlusion. Twenty-one days later, the systolic and diastolic function were evaluated by echocardiography; spectral analysis of the systolic arterial pressure (SAPV) and heart rate variability (HRV) were assessed. After the recording period, the infarct size (IS) was evaluated.

RESULTS: The INF group presented greater cardiac dysfunction and increased sympathetic modulation of the SAPV, as well as decreased alpha index and worse vagal modulation of the HRV. The SEV group exhibited attenuation of the systolic and diastolic dysfunction and preserved vagal modulation (square root of the mean squared differences of successive R-R intervals and high frequency) of HRV, as well as a smaller IS.

CONCLUSION: Sevoflurane preconditioning better preserved the cardiac function and autonomic modulation of the heart in postacute myocardial infarction period.

Key words: Autonomic Nervous System. Heart Rate. Myocardial Infarction. Ischemic Preconditioning, Myocardial. Rats. 


\section{Introduction}

General inhaled anesthesics, with the exception of nitrous oxide, have been studied for their cardioprotective effects since the demonstration that enflurane prevents post-ischemic ventricular dysfunction after global myocardial ischemia in isolated rat hearts ${ }^{1}$. The effects of Anesthetics as cardioprotective agents are well-known and anaesthesic preconditioning (APC) is capable of a reduction of infarct size and mortality after myocardial infarction $^{2,3}$, troponin I release after coronary artery bypass graft surgery ${ }^{4}$ and prevention of acute kidney injury ${ }^{5}$. However, little is known on how APC influences the autonomic modulation of the heart after the acute phase of a myocardial ischemia-reperfusion.

Currently, the study of heart rate variability (HRV) is an accepted method for the functional assessment of cardiovascular autonomic modulation. In cardiovascular disease, especially during the post-acute myocardial infarction period, the HRV decreases and its change is associated with higher adverse outcome ${ }^{6}$. HRV index is also accepted as a predictor of mortality and has been associated with reduced vagal modulation and increased sympathetic modulation, as well as a decrease in baroreflex sensitivity ${ }^{7,8}$.

Since APC protects the myocardial tissue after an acute myocardial infarction, we tested the hypothesis that myocardial ischemia-reperfusion with sevoflurane APC would present better autonomic and cardiac function indexes after the acute phase of a myocardial ischemia-reperfusion.

\section{Methods}

The Ethics Committee of the Hospital das Clinicas da Faculdade de Medicina da Universidade de São Paulo aproved the experimental protocol (CAPPesq-HCFMUSP, $n^{\circ}$ 157/06). The animals were treated in accordance with the National Institute of Health guidelines for the care, handling and use of laboratory animals.

Twenty male Wistar rats weighing 250-350 grams were used in this study. During the experimental period, the animals were confined in Plexiglas cages with free access to food and water in an environment that was controlled for temperature, humidity and exposure to artificial light, with a 12-hour light-dark cycle. The animals were randomly allocated into three groups: control $(\mathrm{CON}, \mathrm{n}=10)$, infarcted (INF, $\mathrm{n}=5)$ and myocardial infarction rats treated with sevoflurane $(\mathrm{SEV}=5)$.

\section{Experimental protocol}

The experimental design used in this investigation is presented in Figure 1. The animals were randomly assigned to one of three experimental groups. Rats in the SEV group were treated with 1 MAC (2.2\%) sevoflurane ${ }^{9}$ (Forane, Abbott) in a calibrated vaporizer (Intermed Penlon Sigma Delta, Abbott) during 30 minutes before the induction of regional myocardial ischemia ${ }^{3}$. Rats in the INF group were exposed to room air only. Rats in the INF and SEV groups underwent 60 minutes of occlusion of the left coronary artery followed by reperfusion.

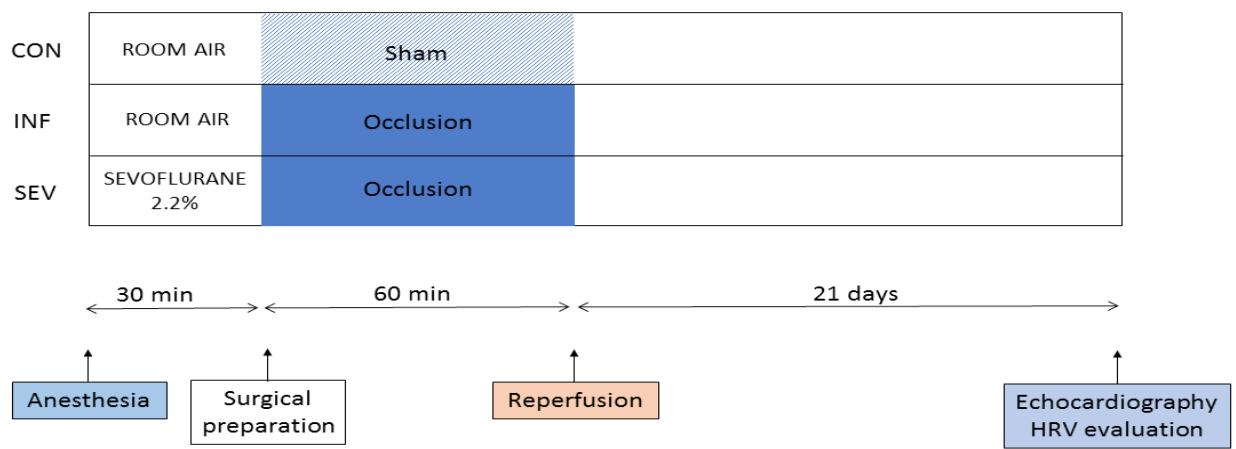

FIGURE 1 - Schematic illustration depicting the experimental protocol. CON=control group; INF=infarcted group; SEV=sevoflurane group.

The animals underwent general anaesthesia with sodium pentobarbital $(50 \mathrm{mg} / \mathrm{kg})$ administered intraperitoneally for catheterization of the femoral vein. Once catheterized, intravenous sodium pentobarbital was continuously administered $(20 \mathrm{mg} /$ $\mathrm{kg} / \mathrm{h}$ until the end of reperfusion period). The animals lungs were ventilated (Rodent Ventilator model 683, Harvard Apparatus,
South Natick, MA, USA) with an inspired oxygen fraction of 0.21 . The respiratory rate and tidal volume were maintained between 60 and 65 movements per minute and $10 \mathrm{ml} / \mathrm{kg}$ of body weight, respectively. The body temperature was maintained at $37^{\circ} \mathrm{C}$ using a thermal plate. Thoracotomy was performed in the fifth intercostal space to allow visualization of the pericardial 
sac, which was carefully dissected to visualize the vessels in the epicardium. After dissection, ischemia was performed with a 6-0 mononylon suture around the base of the left anterior descending coronary artery. A resultant area of ischemia was observed just below the thread. This area was recognized visually as ischemic by the lightened color of the region. After 60 minutes, the suture was released for reperfusion. This procedure was performed by the same researcher for all of the animals. Upon completion of the protocol, the chest wall and skin were sutured. The control group was submitted only to pentobarbital sodium anaesthesia and thoracotomy (sham operated). The animals were treated with a single dose of penicillin (Benzetacil, Fontoura-Wyeth, 40.000 UI/ $\mathrm{Kg}$ ) as well as ketoprofen (Ketofen inj.1\%, Merial, $5 \mathrm{mg} / \mathrm{kg} / 24 \mathrm{~h}$ ) for three days.

Nineteen days following completion of the protocol described above, the animals were anesthetized (sodium pentobarbital $40 \mathrm{mg} / \mathrm{kg}$ ) to implant catheters (PE10) in the femoral artery for direct measurement of arterial pressure (AP). The recordings were made two days after implantation of the catheters, with the animals in a conscious state and freely moving in the cages. The arterial cannula was connected to a strain-gauge transducer (P23Db, Gould-Statham, Oxnard, CA), and the AP signals were recorded over a 30 -minute period by a microcomputer equipped with an analog-to-digital converter board (Windaq, $2 \mathrm{kHz}$ sampling frequency; Dataq Instruments, Inc., Akron, OH). The recorded data were analyzed on a beat-to-beat basis to quantify changes in the mean $\mathrm{AP}$ and $\mathrm{HR}^{10}$. HRV was measured using the standard deviation of the basal HR recording period.

\section{Heart rate variability and arterial blood pressure in the time and frequency domain}

The parameters analyzed in the time domain consisted of the mean values for HRV, systolic arterial pressure (SAP), and systolic arterial pressure variability (SAPV), which were quantified by the total variance. It was calculated the square root of the mean squared differences of successive R-R intervals (RMSSD), a representative index of vagal modulation. For frequency domain analysis using Fast Fourier Transform, the power was measured using the periodogram method of Welsh with a 16,384-timepoint series for pulse and blood pressure, a Hanning window of 512 points and a $50 \%$ overlap (MATLAB 6.0, Mathworks, Inc). The power of the signals in the low frequency (LF, 0.20 to $0.75 \mathrm{~Hz}$ ) and high frequency (HF, 0.75 to $4.0 \mathrm{~Hz}$ ) ranges were calculated by integrating the power in the bands of interest; the results were expressed as absolute values and normalized values. For normalization, the powers of the LF (LFnu) and HF (HFnu) bands were divided by the variance minus the power in the very low frequency band ${ }^{11}$. Coupling between the pulse interval and systolic arterial pressure was estimated by the coherence function. A consistency $(\mathrm{K})$ value greater than 0.5 was considered significant. The records were analyzed beat-by-beat to quantify changes in the blood pressure and pulse interval. Beatto-beat values of the SAP and R-R interval were used to estimate the cardiac baroreflex sensitivity (BRS) by spectral analysis, using the alpha index for the low-frequency band $(0.20-0.75 \mathrm{~Hz})$. The coherence between the pulse interval (PI) and the SAP signal variability was assessed via cross-spectral analysis. The alpha index was calculated only when the magnitude of the squared coherence between the PI and SAP signals exceeded 0.5 (range, $0-1)$ in the LF band. After the coherence calculation, the alpha index was obtained from the square root of the ratio between the PI and SAP variability in the two major LF bands ${ }^{12}$.

\section{Echocardiographic evaluation}

After the recording period, animal were anesthetized with $2.2 \%$ sevoflurane and echocardiography was performed by an observer who was blinded to the treatment group, according to the guidelines of the American Society of Echocardiography. Images were obtained using a 10-14 MHz linear transducer in a SEQUOIA 512 machine (ACUSON, Mountain View, CA, USA) to measure systolic function evaluated by ejection fraction (LVEF\%) and fractional shortening (LVFS\%); and diastolic function evaluated by the LV absolute and normalized isovolumetric relaxation time (IVRT and nIVRT), as well as by the deceleration time of E-wave. A global index was quantified by the myocardial performance index $(\mathrm{MPI})^{13}$.

\section{Determination of the infarct size}

After echocardiographic evaluation, the animals were submitted to Anaesthesic overdose, and the heart was quickly removed and placed in a system of non-recirculating retrograde perfusion with warm $\left(37^{\circ} \mathrm{C}\right)$ saline. The middle region of the left ventricle (LV) was sectioned at $\approx 2 \mathrm{~mm}$, and the sections were placed in buffer solution ( $\mathrm{pH} 7.4)$ of $1 \%$ triphenyltetrazolium chloride (TTC) at $37^{\circ} \mathrm{C}$ during 20 minutes $^{14}$. The sections were individually photographed with a digital camera (Sony Cybershot, 7.2 mega pixels) and analyzed by Image Tool (Image Tool version 3.0, UTHSCSA, San Antonio, TX, USA). The infarct sizes (IS) were expressed as a percentage of the total LV area ${ }^{15}$. 


\section{Statistical analysis}

The data were expressed as mean \pm SEM. One-way ANOVA was used to compare the groups, followed by the StudentNewman-Keuls test, when necessary. The myocardial infarct size was compared using an unpaired Student's t-test. Correlations between IS and LF SAPV, RMSSD and HRV were performed by Pearson correlation coefficient. The significance level was $5 \%$.

\section{Results}

\section{Hemodynamics and HRV in the time domain}

The values obtained for the hemodynamic, pulse interval, SAP and SAPV are presented in Table 1. The AP and pulse interval values were not significantly different among the studied groups. The SAPV, HRV and RMSSD were similar in the SEV and CON groups. However, the INF group presented lower HRV and RMSSD and higher SAPV compared with the other groups.

TABLE 1 - Time-domain autonomic variables in the control (CON), infarcted (INF) and sevoflurane (SEV) groups of awake rats 21 days post-infarction.

\begin{tabular}{cccc}
\hline $\begin{array}{c}\text { Variable/groups } \\
(\boldsymbol{n})\end{array}$ & $\boldsymbol{C O N}(\mathbf{1 0})$ & $\boldsymbol{I N F ( 5 )}$ & $\boldsymbol{S E V ( 5 )}$ \\
\hline SAP $(\mathrm{mmHg})$ & $110.04 \pm 6.54$ & $124.16 \pm 5.8$ & $114.69 \pm 4.25$ \\
SAPV $\left(\mathrm{mmHg}^{2}\right)$ & $23.50 \pm 2.9$ & $36.56 \pm 5.6^{*} \#$ & $18.72 \pm 2.7$ \\
PI (ms) & $179.6 \pm 4.07$ & $176.6 \pm 5.76$ & $192.8 \pm 6.21$ \\
HRV (ms $\left.{ }^{2}\right)$ & $100.13 \pm 14$ & $38.28 \pm 10^{*} \#$ & $109.27 \pm 5.7$ \\
RMSSD (ms) & $6.79 \pm 0.17$ & $5.12 \pm 0.72 * \#$ & $7.51 \pm 0.1$ \\
\hline
\end{tabular}

Results are expressed as the mean \pm SEM. One-way ANOVA, ${ }^{*} \mathrm{P}<0.05$ vs. CON; \# $\mathrm{P}<0.05$ vs. SEV.

SAP - systolic arterial pressure $(\mathrm{mmHg})$; SAPV - systolic arterial pressure variability $\left(\mathrm{mmHg}^{2}\right)$; PI - pulse interval (ms); HRV - heart rate variability $\left(\mathrm{ms}^{2}\right)$; RMS$\mathrm{SD}$ - square root of pulse intervals adjacent to the square (ms).

Spectral analyses of the heart rate and of the systolic arterial pressure

The results for these variables are presented on Table 2 . The absolute HF of the HRV was reduced in the INF rats compared with the CON and SEV groups. The values for the LF band of HRV revealed no significant differences among the studied groups. The values for LFnu and HFnu of the HRV revealed no significant differences among the studied groups.
TABLE 2 - Frequency domain autonomic variables for the control (CON), infarcted (INF) and sevoflurane (SEV) groups measured in awake rats 21 days post-infarction.

\begin{tabular}{cccc}
\hline $\begin{array}{c}\text { Variable/groups } \\
\text { (n) }\end{array}$ & CON(10) & INF(5) & SEV(5) \\
\hline $\begin{array}{c}\text { Heart Rate } \\
\text { Variability }\end{array}$ & & & \\
LF (ms $\left.{ }^{2}\right)$ & $4.04 \pm 0.6$ & $3.27 \pm 0.6$ & $4.62 \pm 0.4$ \\
LFnu (NU) & $22.63 \pm 2.2$ & $29.18 \pm 2.9$ & $25.33 \pm 0.9$ \\
HF (ms $\left.{ }^{2}\right)$ & $13.09 \pm 0.8$ & $8.57 \pm 2.0 * \#$ & $13.45 \pm 0.9$ \\
HFnu (NU) & $77.37 \pm 2.2$ & $70.82 \pm 2.9$ & $74.67 \pm 0.9$ \\
LF/HF & $0.25 \pm 0.04$ & $0.42 \pm 0.05^{*}$ & $0.34 \pm 0.02$
\end{tabular}

Systolic Arterial Pressure Variability

$\begin{array}{cccc}\mathrm{LF}\left(\mathrm{mmHg}^{2}\right) & 2.62 \pm 0.8 & 5.39 \pm 1.6^{*} & 3.98 \pm 0.07 \\ \mathrm{HF}\left(\mathrm{mmHg}^{2}\right) & 1.42 \pm 0.21 & 1.54 \pm 0.48 & 1.88 \pm 0.19 \\ \begin{array}{l}\text { Alpha index } \\ (\mathrm{ms} / \mathrm{mmHg})\end{array} & 1.32 \pm 0.18 & 0.91 \pm 0.21^{*} & 1.07 \pm 0.05\end{array}$

Results are expressed as the mean \pm SEM. One-way ANOVA, * $\mathrm{P}<0.05$ vs. CON $\# \mathrm{P}<0.05$ vs. SEV.

$\mathrm{LF}$ - low-frequency absolute value of $\mathrm{HRV}\left(\mathrm{ms}^{2}\right) ; \mathrm{LF}$ - low-frequency normalized unit (NU); HF - high-frequency absolute value of $\mathrm{HRV}\left(\mathrm{ms}^{2}\right)$; $\mathrm{HF}$ - high-frequency normalized unit (NU); LF/HF - autonomic balance; LF - low-frequency absolute value of SAPV $\left(\mathrm{mmHg}^{2}\right)$; HF - high-frequency absolute value of SAPV $\left(\mathrm{mmHg}^{2}\right)$; Alpha index - baroreflex sensitivity ( $\mathrm{ms} / \mathrm{mmHg}$ ).

Regarding the spectral analysis of the systolic arterial pressure, there was a decrease in the alpha index for the INF rats when compared with the $\mathrm{CON}$ rats and an increase on the absolute values of the LF component of the SAPV (LFSAPV) band compared with the CON group.

\section{Echocardiography function evaluation}

The results of the echocardiography evaluation are presented in Table 3. The systolic function, which was expressed by LVEF\% and by LVFS\%, was lower in the INF group than in the SEV and CON animals. However, the SEV group exhibited lower $\mathrm{LVEF} \%$ and $\mathrm{LVFS} \%$ values than the CON group. According to the diastolic function data, the INF group had a higher IVRT, nIVRT and $\mathrm{E}$ wave deceleration time compared with the CON and SEV groups. No significant difference in diastolic function was found between the CON and SEV groups. The MPI was higher in the INF group than in the CON group. 
TABLE 3 - Echocardiographic data variables for the control (CON), infarcted (INF) and sevoflurane (SEV) groups measured in awake rats 21 days post-infarction.

\begin{tabular}{cccc}
\hline Variable/groups (n) & CON(10) & INF(5) & SEV(5) \\
\hline Systolic Function & & & \\
LVEF(\%) & $85 \pm 2$ & $50 \pm 3^{*} \#$ & $67 \pm 2^{*}$ \\
LVFS(\%) & $50 \pm 6$ & $24 \pm 5^{*} \#$ & $39 \pm 2^{*}$ \\
Diastolic Function & & & \\
IVRT(ms) & $20 \pm 0.53$ & $27 \pm 1.01^{*}$ & $21 \pm 0.72$ \\
nIVRT (ms) & $1.75 \pm 0.04$ & $2.03 \pm 0.05^{*}$ & $1.68 \pm 0.06$ \\
E-wave Deceleration & $1.84 \pm 0.19$ & $2.82 \pm 0.32^{*}$ & $1.96 \pm 0.21$ \\
Time (ms) & & & \\
Global Index (MPI) & $0.34 \pm 0.03$ & $0.52 \pm 0.04^{*}$ & $0.44 \pm 0.05$ \\
\hline
\end{tabular}

Results are expressed as the mean \pm SEM. One-way ANOVA, * $\mathrm{P}<0.05$ vs. CON; \# $\mathrm{P}<0.05$ vs. SEV. Systolic function was evaluated by the ejection fraction (LVEF\%), fractional shortening (LVFS\%), and the diastolic function was evaluated by the LV absolute and normalized isovolumetric relaxation time (IVRT and nIVRT), as well as by the deceleration time of the E-wave. A global index was quantified by the myocardial performance index (MPI).

\section{Myocardial infarction size}

The results obtained from the APC with sevoflurane are presented in Figure 2. The IS size was significantly reduced in the SEV group $(12.08 \% \pm 1.05 \%)$ compared with the INF group $(23.13 \% \pm 4.34 \%)$.

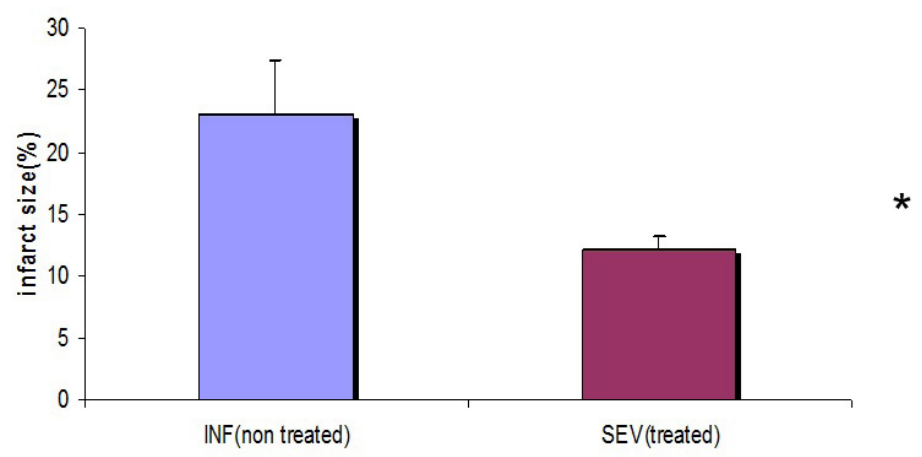

FIGURE 2 - Effect of sevoflurane treatment (SEV) on the myocardial infarct size observed 21 days after coronary occlusion. Data are expressed as the mean $\pm \mathrm{SEM}$. Unpaired t-test $* \mathrm{P}<0.01$ vs. SEV. SEV $=$ sevoflurane group; $\mathrm{INF}=$ myocardial infarct group.

A positive correlation was found between the LF band of HRV and IS, whereas negative correlations were found between RMSSD and IS, as well as between HRV and IS, as shown in Figure 3.
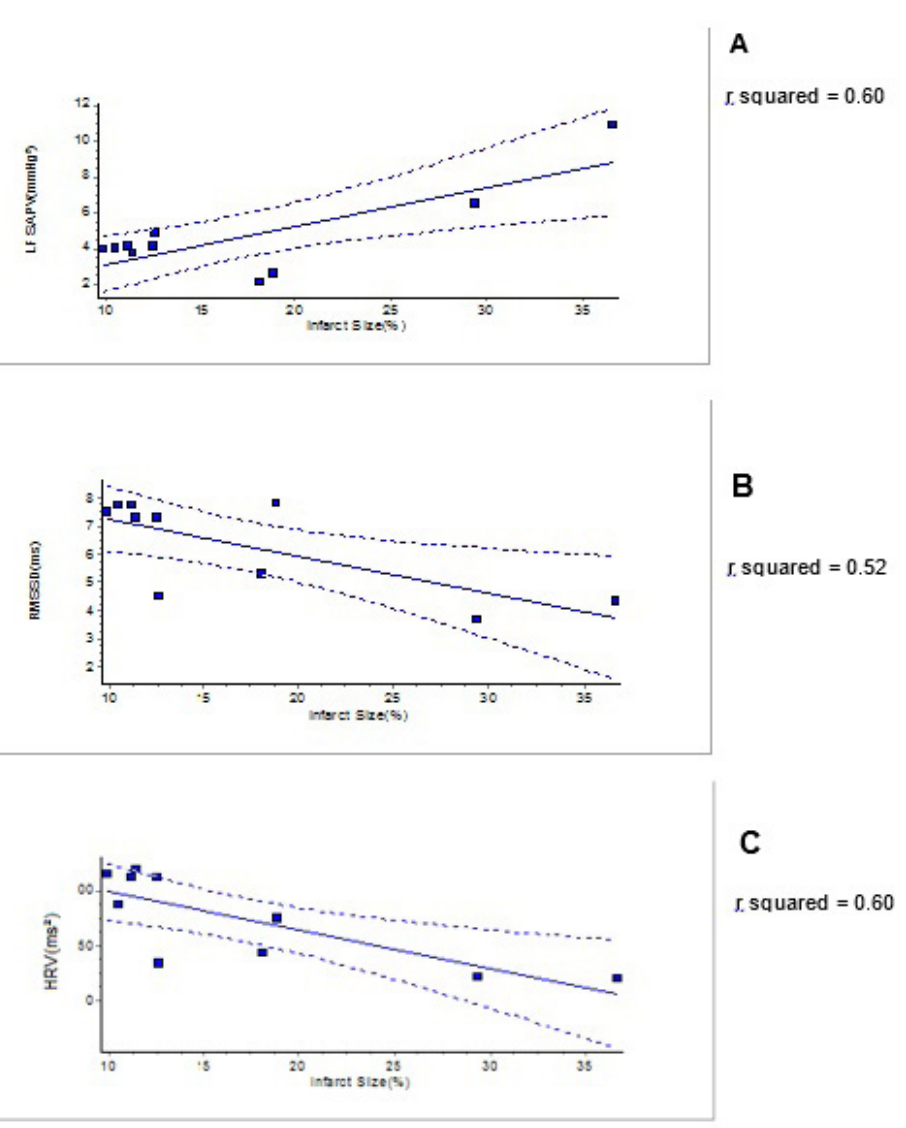

FIGURE 3 - (A) Pearson correlation between LFSAPV $\left(\mathrm{mmHg}^{2}\right)$ and the infarct size (\%) in the myocardial infarct and sevoflurane groups. The $\mathrm{p}$ value was $<0.008$ (considered significant). (B). Pearson correlation between RMSSD (ms) and the infarct size (\%) in the myocardial infarct and sevoflurane groups. $\mathrm{p}<0.01$ (considered significant). (C) Pearson correlation between HRV $\left(\mathrm{ms}^{2}\right)$ and the infarct size (\%) in the myocardial infarct and sevoflurane groups. The $\mathrm{p}$ value was $<0.008$ (considered significant).

\section{Discussion}

The main findings from the present study are that sevoflurane preconditioning preserved the autonomic control of circulation and attenuated the cardiac dysfunction in chronically infarcted rats. This study also demonstrated that APC with sevoflurane reduced the infarct size, revealing a positive correlation between the infarct size and autonomic control of the circulation. These results provide evidence for the effects of pharmacological preconditioning with sevoflurane, as demonstrated by a reduction in the IS, improved cardiac function and better autonomic modulation. Based on these results, we suppose that sevoflurane preconditioning was responsible for the smaller infarction area, thus preserving autonomic control of circulation and cardiac function. 
Heart failure after a myocardial infarction is common and it is expected that over $20 \%$ of the patients that suffer an MI will develop this entity ${ }^{16}$. Ventricular dysfunction leads to a low cardiac output, triggering mechanisms that will lead to activation of sympathetic nervous system and peripheral vasoconstriction ${ }^{17}$. By activating these mechanisms, there is an increase in norepinephrine levels in order to provide inotropic support and maintenance of the mean arterial pressure. In patients with heart failure, the activation of these compensatory systems are translated as a markedly reduced HRV, which is related to the severity and prognosis of these patients ${ }^{18,19}$. Thus, in heart failure patients after a MI, a shift towards a sympathetic dominance and a reduced parasympathetic activity are expected ${ }^{20}$. In our study, the infarcted animals with no preconditioning presented similar findings: decreased HRV, with increased sympathetic activity (LF component of SAPV) and decreased parasympathetic activity (RMSSD and HF component of HRV $)^{21,22}$. These findings are also consistent with those on functional evaluation of the heart by echocardiography, where the infarcted animals had systolic and diastolic dysfunction.

The sympathetic activity implies on the release of two main neurotransmiters: epinephrine and norepinephrine. Both of these catecholamines have been shown to exert a direct toxic effect, leading to myocyte lesion and apoptosis ${ }^{23,24}$. Norepinephrine binds to myocardial $\beta$-adrenergic receptors, which increases the levels of cyclic adenosine monophosphate (cAMP), by the activation of adenylate cyclase ${ }^{25}$. Elevated levels of cAMP precede an influx of calcium inside the myocyte by the phosphorylation of L-type calcium channels by the protein kinase $\mathrm{A}^{25}$. This influx is able to increase the sarcoplasmic reticulum release of calcium, leading to enhanced myocardial contractility. However, increased levels of intracellular calcium are also linked to myocyte apoptosis, especially after an ischemic event ${ }^{23}$. Myocyte apoptosis might also be responsible for heart failure after an $\mathrm{MI}^{23}$. Due to these facts, norepinephrine release by an increased sympathetic activity during ischemia or infarction has been linked to ventricular fibrillation, sustained ventricular tachycardia, and increased mortality ${ }^{7,26,27}$. On the other hand, increased vagal activity decreases the possibility of ventricular fibrillation ${ }^{26}$. Thus, it is desirable to have a decreased sympathetic activity with a predominance of parasympathetic activity.

Although some studies have implied that the LF component of $\mathrm{HRV}$ as well as the $\mathrm{LF} / \mathrm{HF}$ ratio might reflect the parasympathetic cardiac modulation or the baroreflex ${ }^{13,28}$, the LF component has usually been associated with sympathetic activity $^{29,30}$. In the present study, there was an increase in the LF/HF component of HRV in the infarcted animals. Since the absolute LF component of the HRV was not different between groups (SEV and INF) and the absolute HF of HRV (parasympathetic) was decreased in the non APC infarcted animals, the change on the LF/HF ratio in the INF group animals was due to a decreased parasympathetic activity. These results show a relative predominance of the sympathetic activity in the INF group animals. This finding is also confirmed by the increase of the LF component of the SAPV, which is related to sympathetic activity on the vessels ${ }^{21,22}$. With the sevoflurane preconditioning, the increased sympathetic activity was not observed, indicating a better control of the autonomic modulation and likely better survival after myocardial infarction. The sevoflurane APC also resulted in a decreased IS, which is probably the main mechanism for autonomic function preservation, reinforced by the direct relationship between the IS area and the autonomic variables (LF SAPV, RMSSD and HRV).

Activation of sympathetic nervous system has also been linked to changes in peripheral baroreceptor and chemoreceptor reflexes ${ }^{17}$. The arterial baroreflex system is one of the most powerful and rapidly acting mechanisms for controlling blood pressure and autonomic activity. When impaired, it may be indirectly associated with target organ lesions since surgical removal of the carotid sinus and aortic arch baroreceptors leads to an inability to buffer moment-to-moment changes in pressure, which, in turn, causes increased blood pressure variability and decreased $\mathrm{HRV}^{31}$ Depression of the baroreflex sensitivity and sympathetic overactivity have been demonstrated following myocardial infarction in humans ${ }^{26}$ and are associated with poor outcomes ${ }^{32}$. In fact, changes in sympathetic activity and baroreflex sensitivity have been implicated in decreased HRV and increased mortality after myocardial infarction ${ }^{32}$. Along with better autonomic control, we observed that sevoflurane preconditioning maintained the alpha-index, which represents the baroreflex sensitivity.

The main limitations of our study were the small sample size, which consisted of only twenty animals, and the non-blinded protocol. Therefore, additional studies are necessary to evaluate whether these findings have a clinically significant impact on the mortality.

Based on these findings from the spectral analysis of the HR, SAPV, echocardiography, IS calculation and baroreflex sensitivity, we conclude that sevoflurane preconditioning preserves the autonomic control of circulation and the cardiac function in chronic myocardial infarction. 


\section{References}

1. Freedman BM, Hamm DP, Everson CT, Wechsler AS, Christian $\mathrm{CM}, 2^{\text {nd }}$. Enflurane enhances postischemic functional recovery in the isolated rat heart. Anesthesiology. 1985; 62:29-33. PMID: 3966666.

2. Bignami E, Greco T, Barile L, Silvetti S, Nicolotti D, Fochi O, Cama E, Costagliola R, Landoni G, Biondi-Zoccai G, Zangrillo A. The effect of isoflurane on survival and myocardial infarction: a metaanalysis of randomized controlled studies. J Cardiothorac Vasc Anesth. 2013.;27:50-8. PMID: 22819469.

3. Toller WG, Kersten JR, Pagel PS, Hettrick DA, Warltier DC. Sevoflurane reduces myocardial infarct size and decreases the time threshold for ischemic preconditioning in dogs. Anesthesiology. 1999;91:1437-46. PMID: 10551596.

4. $\mathrm{Yu} \mathrm{CH}$, Beattie WS. The effects of volatile anesthetics on cardiac ischemic complications and mortality in CABG: a meta-analysis. Can J Anaesth. 2006;53:906-18. PMID: 16960269.

5. Cai J, Xu R, Yu X, Fang Y, Ding X. Volatile anesthetics in preventing acute kidney injury after cardiac surgery: a systematic review and meta-analysis. J Thorac Cardiovasc Surg. 2014;148:3127-36. PMID: 25218542.

6. Buccelletti E, Gilardi E, Scaini E, Galiuto L, Persiani R, Biondi A, Basile F, Silveri NG. Heart rate variability and myocardial infarction: systematic literature review and metanalysis. Eur Rev Med Pharmacol Sci. 2009;13:299-307. PMID: 19694345.

7. Heart rate variability. Standards of measurement, physiological interpretation and clinical use. Task Force of the European Society of Cardiology and the North American Society of Pacing and Electrophysiology. Circulation. 1996;93:1043-65. PMID: 8598068.

8. Malik M, Cripps T, Farrell T, Camm AJ. Prognostic value of heartrate variability after myocardial-infarction - a comparison of different data-processing methods. Med Biol Eng Comput. 1989;27:603-11.

9. Kashimoto S, Furuya A, Nonaka A, Oguchi T, Koshimizu M, Kumazawa T. The minimum alveolar concentration of sevoflurane in rats. Eur J Anaesthesiol. 1997;14:359-61. PMID: 9253561.

10. Harthmann AD, De Angelis K, Costa LP, Senador D, Schaan BD, Krieger EM, Irigoyen MC. Exercise training improves arterial baro- and chemoreflex in control and diabetic rats. Auton Neurosci. 2007;133:115-20. PMID: 17196889.

11. Pagani M, Lombardi F, Guzzetti S, Rimoldi O, Furlan R, Pizzinelli P, Sandrone G, Malfatto G, Dell'Orto S, Piccaluga E, Turiel M, Baselli G, Cerutti S, Malliani A. Power spectral analysis of heart rate and arterial pressure variabilities as a marker of sympatho-vagal interaction in man and conscious dog. Circ Res. 1986;59:178-93. PMID: 2874900.

12. Zamo FS, Lacchini S, Mostarda C, Chiavegatto S, Silva IC, Oliveira EM, Irigoyen MC. Hemodynamic, morphometric and autonomic patterns in hypertensive rats - Renin-Angiotensin system modulation. Clinics (Sao Paulo). 2010;65:85-92. PMID: 20126350.

13. Mostarda C, Rodrigues B, Vane M, Moreira ED, Rosa KT, Moraes-Silva IC, Lacchini S, Casarini DE, De Angelis K, Irigoyen MC. Autonomic impairment after myocardial infarction: role in cardiac remodelling and mortality. Clin Exp Pharmacol Physiol. 2010;37:447-52. PMID: 19878213.

14. Fishbein MC, Meerbaum S, Rit J, Lando U, Kanmatsuse K, Mercier JC, Corday E, Ganz W. Early phase acute myocardial infarct size quantification: validation of the triphenyl tetrazolium chloride tissue enzyme staining technique. Am Heart J. 1981;101:593-600. PMID: 6164281.

15. Spadaro J, Fishbein MC, Hare C, Pfeffer MA, Maroko PR. Characterization of myocardial infarcts in the rat. Arch Pathol Lab Med. 1980;104:179-83. PMID: 6892678.

16. Spencer FA, Meyer TE, Gore JM, Goldberg RJ. Heterogeneity in the management and outcomes of patients with acute myocardial infarction complicated by heart failure: the National Registry of Myocardial Infarction. Circulation. 2002;105:2605-10. PMID: 12045165 .

17. Triposkiadis F, Karayannis G, Giamouzis G, Skoularigis J, Louridas G, Butler J. The sympathetic nervous system in heart failure physiology, pathophysiology, and clinical implications. J Am Coll Cardiol. 2009;54:1747-62. PMID: 19874988.

18. Toepfer M, Meyer K, Maier P, Dambacher M, Theisen K, Roskamm $\mathrm{H}$, Frey AW. Heart rate variability and autonomic balance in patients with different stages of severe congestive heart failure. Clin Sci (Lond). 1996;91 Suppl:117. PMID: 8813849.

19. Palacios M, Friedrich $H$, Gotze $C$, Vallverdu $M$, de Luna $A B$, Caminal P, Hoyer D. Changes of autonomic information flow due to idiopathic dilated cardiomyopathy. Physiol Meas. 2007;28:677-88. PMID: 17664621.

20. Florea VG, Cohn JN. The autonomic nervous system and heart failure. Circ Res. 2014;114:1815-26. PMID: 24855204.

21. Stauss HM. Identification of blood pressure control mechanisms by power spectral analysis. Clin Exp Pharmacol Physiol. 2007;34:3628. PMID: 17324151

22. Stein PK, Bosner MS, Kleiger RE, Conger BM. Heart rate variability: a measure of cardiac autonomic tone. Am Heart J. 1994;127:137681. PMID: 8172068.

23. Communal C, Singh K, Pimentel DR, Colucci WS. Norepinephrine stimulates apoptosis in adult rat ventricular myocytes by activation of the beta-adrenergic pathway. Circulation. 1998;98:1329-34. PMID: 9751683

24. da Luz VF, Otsuki DA, Gonzalez MM, Negri EM, Caldini EG, Damaceno-Rodrigues NR, Malbouisson LM, Viana BG, Vane MF, Carmona MJ. Myocardial protection induced by fentanyl in pigs exposed to high-dose adrenaline. Clin Exp Pharmacol Physiol. 2015;42:1098-107. PMID: 26173999.

25. Vaseghi M, Shivkumar K. The role of the autonomic nervous system in sudden cardiac death. Prog Cardiovasc Dis. 2008;50:404-19. PMID: 18474284.

26. Kleiger RE, Miller JP, Bigger JT, Jr., Moss AJ. Decreased heart rate variability and its association with increased mortality after acute myocardial infarction. Am J Cardiol. 1987;59:256-62. PMID: 3812275 .

27. Odemuyiwa O, Malik M, Farrell T, Bashir Y, Poloniecki J, Camm J. Comparison of the predictive characteristics of heart rate variability index and left ventricular ejection fraction for all-cause mortality, arrhythmic events and sudden death after acute myocardial infarction. Am J Cardiol. 1991;68:434-9. PMID: 1872267.

28. Martelli D, Silvani A, McAllen RM, May CN, Ramchandra R. The low frequency power of heart rate variability is neither a measure of cardiac sympathetic tone nor of baroreflex sensitivity. Am J Physiol Heart Circ Physiol. 2014;307:H1005-12. PMID: 25063795.

29. Pagani M, Montano N, Porta A, Malliani A, Abboud FM, Birkett C, Somers VK. Relationship between spectral components of cardiovascular variabilities and direct measures of muscle sympathetic nerve activity in humans. Circulation. 1997;95:1441-8. PMID: 9118511.

30. Furlan R, Porta A, Costa F, Tank J, Baker L, Schiavi R, Robertson D, Malliani A, Mosqueda-Garcia R. Oscillatory patterns in sympathetic neural discharge and cardiovascular variables during orthostatic stimulus. Circulation. 2000;101:886-92. PMID: 10694528.

31. Floras JS, Hassan MO, Jones JV, Osikowska BA, Sever PS, Sleight P. Consequences of impaired arterial baroreflexes in essential hypertension: effects on pressor responses, plasma noradrenaline and blood pressure variability. J Hypertens. 1988;6:525-35. PMID: 3171169. 
32. La Rovere MT, Bigger JT, Jr., Marcus FI, Mortara A, Schwartz PJ. Baroreflex sensitivity and heart-rate variability in prediction of total cardiac mortality after myocardial infarction. ATRAMI (Autonomic Tone and Reflexes After Myocardial Infarction) Investigators. Lancet. 1998;351:478-84. PMID: 9482439.

\section{Correspondence:}

Prof. Dra. Denise Aya Otsuki

Laboratório de Anestesiologia (LIM-08)

Faculdade de Medicina, USP

Avenida Dr. Arnaldo, 455

01246-903 São Paulo - SP Brasil

Tel.: (55 11)3061-7293

lim08@usp.br

Received: Jan 14, 2016

Review: Mar 10, 2016

Accepted: Apr 17, 2016

Conflict of interest: none

Financial sources: CAPES and FAPESP $\left(n^{\circ}\right.$ 2006/55220-1)

${ }^{1}$ Research performed at Hypertension Unit, Experimental Division, Instituto do Coração (InCor), Hospital das Clínicas, Faculdade de Medicina, Universidade de São Paulo (USP), Brazil. 